\title{
Utilisation des techniques à membrane pour la séparation, la purification et la fragmentation des protéines laitières
}

\author{
par \\ J.L. MAUBOIS* et G. BRULE*
}

\section{$R$ és u m é}

L'implantation de la technique d'ultrafiltration sur membrane au cours de la dernière décennie se caractérise par l'accroissement exponentiel des surfaces installées $\left(70000 \mathrm{~m}^{2}\right.$ en 1981). Grâce aux progrès accomplis en matière de membranes ( 3 générations) et d'appareillages, grâce aussi à une meilleure compréhension des mécanismes gouvernant la formation et l'évolution de la membrane dynamique ce qui a permis de mettre au point différents prétraitements du lactosérum, une multiplication par 3 à 4 des débits de perméation a été réalisée. Les concentrés de protéines de lactosérum ont trouvé $\mathrm{du}$ fait de leur exceptionnelle qualité nutritionnelle et de leurs propriétés fonctionnelles des utilisations très larges et diversifiées en alimentation humaine.

L'ultrafiltration du lait en vue de sa transformation en fromage est maintenant largement utilisée à l'échelle industrielle $(120000 \mathrm{t}$ en 1981) pour la production de fromages à pâte fraîche, de fromages à pâte molle et de fromage blanc saumuré (Féta). Les progrès récents en matière d'équipements ont rendu réalisables en site industriel l'obtention des préfromages destinés à la transformation en fromages à pâte demi-dure et la substitution de l'ultrafiltre au centrifugeur à caillé. Plus en amont de la filière lait, la fiabilité actuelle des équipements a permis d'envisager une ultrafiltration combinée avec une thermisation sur le lieu de production laitière, opération qui, si elle se généralisait au cours de la prochaine décennie, bouleverserait les données socio-économiques actuelles.

* Laboratoire de Recherches de Technologie Laitière (I.N.R.A.), 65, rue de SaintBrieuc, 35042 Rennes Cedex. 
Sur un autre plan, les biotechnologies à membrane ouvrent des possibilités très diversifiées de valorisation des composants du lait. Grâce aux réacteurs enzymatiques, il est possible de fragmenter les protéines de lactosérum et les caséines et de préparer ainsi des produits correspondant aux besoins nutritionnels de différentes catégories de patients. Les hydrolysats pancréatiques de protéines de lactosérum obtenus par cette technologie se caractérisent par une teneur en acides aminés libres inférieure à $10 \%$ et par une dominance de peptides compris entre le di et le décapeptide. De même, les séquences phosphopeptidiques des caséines isolées et purifiées par un procédé mettant en œuvre à la fois l'hydrolyse enzymatique et leurs propriétés d'agrégation ont un excellent pouvoir chelatant des oligo-éléments minéraux.

Mots clés

Ultrafiltration sur membrane - Lactosérum - Concentrés de protéines Biotechnologies - Phosphopeptides.

Titre abrégé

Ultrafiltration sur membrane dans l'industrie laitière.

\section{S u m m a ry}

Evolution of ultrafiltration membrane areas installed in the world dairy industry during last ten years was exponentially increasing. Important progresses have been made in membrane conception and equipments. Through a better understanding of mechanisms ruling formation and evolution of fouling during ultrafiltration, pretreatments of whey were developed for increasing permeate fluxes. By limiting intramembrane fouling through action on the solubility of calcium salts or by removing insoluble components, permeate flux is multiplied by a factor of 3 or 4 . Whey protein concentrates (W.P.C.) thanks to their high nutritional quality and their functional properties have found very large and diversified utilizations in the food industry for human nutrition.

Milk ultrafiltration for cheesemaking was now largely employed at industrial scale (120000 $t$ in 1981). Fresh and soft cheeses were made through this process but the main application of UF in the cheese industry was for the time being Feta cheese $(92000 \mathrm{t}$ in 1981). Recent progresses in membrane technology such as commercialization of mineral membranes and new membrane support adapted to rheological evolution of highly viscous retentates have made industrially feasible making of semi hard cheeses, direct preparation of a cheese base and substitution of an ultrafilter to a curd separator in the making of fresh cheese or quarg. Actual fiability was sufficiently high that combination of UF with thermization at farm level was envisaged in the purpose to improve bacteriological milk quality 
and also to reduce transport costs but generalization of such an operation leads also to many consequences in dairy economy.

On the other hand, membrane biotechnologies are opening very large and diversified valorizations for milk components. Through enzymatic membrane reactors fragmentation of whey proteins and caseins leads to sophisticated products required for nutrition of patients suffering from intestine, pancreas or liver illnesses; pancreatic hydrolysates obtained by a process recently developed had a free amino acids content less than $10 \%$ and most of the peptides had between 2 and 10 residues. Specific sequences of caseins, the phosphopeptides were isolated by a similar process using enzymic hydrolysis in a membrane reactor and aggregating properties by calcium salts. Solubility and chelating properties of trace elements of so prepared phosphopeptides were found particularly high.

\section{Key words}

Membrane ultrafiltration - Equipments - Whey - Whey protein - Concentrates Biotechnologies - Phosphopeptides.

\section{INTRODUCTION}

L'implantation de la technique d'ultrafiltration sur membrane dans l'industrie laitière mondiale au cours de la décennie qui s'est écoulée peut se caractériser spectaculairement par les deux chiffres suivants: $300 \mathrm{~m}^{2}$ installés en 1971, $70000 \mathrm{~m}^{2}$ en 1981 (fig. 1). Les causes d'insertion de cette technologie nouvelle doivent être recherchées à la fois :

- dans les caractéristiques biochimiques du lait et de ses dérivés (lactosérum notamment). Le tamisage moléculaire de ces liquides n'exige pas, en première approche, l'emploi de membranes à porosité très contrôlée en raison du "trou » existant dans l'échelle de répartition des tailles moléculaires entre le lactose $(0,8 \mathrm{~nm})$ et les plus petites protéines ( $3 \mathrm{~nm}$ pour le monomère de l' $\alpha$-lactalbumine) ;

- dans les acquis de la Science laitière moderne qui font du lait et de ses dérivés les produits alimentaires les mieux connus et de loin, que ce soit au plan des propriétés de leurs composants ou bien en ce qui concerne les effets des traitements technologiques sur ces propriétés. Sur ce plan, il peut être remarqué que l'ultrafiltration sur membrane a constitué à la fois un ensemble d'objectifs de recherche (relation entre les débits de perméation et les caractéristiques de la couche de polarisation; étude de l'interface membrane-rétentat; applications à l'obtention de protéines purifiées, etc.) et une technique nouvelle d'études des interactions entre les composants du lait (interactions protéines-minéraux notamment) ;

- dans les progrès successifs réalisés en matière de membranes et d'équipements les environnant. Trois générations de membranes 


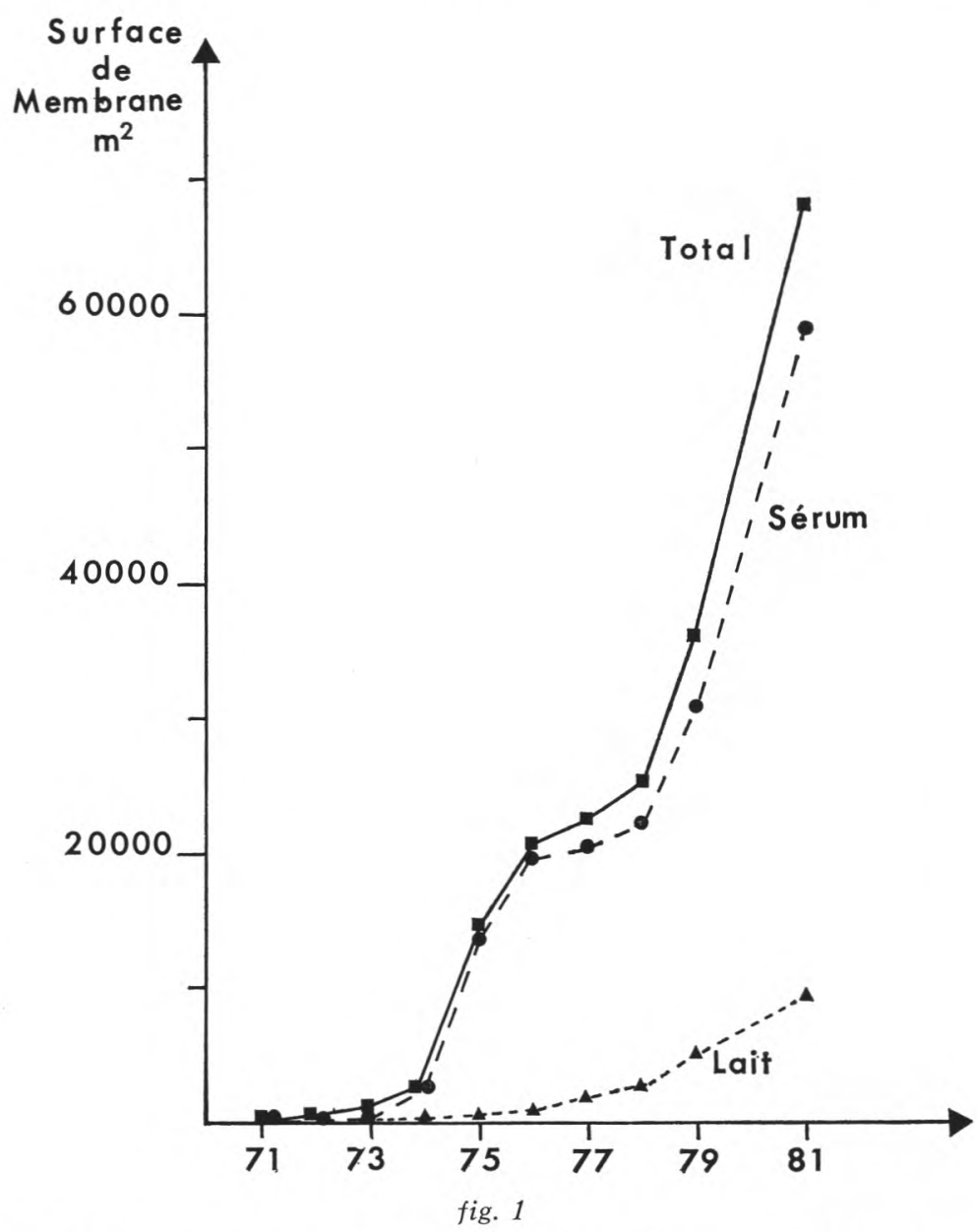

Evolution des surfaces de membranes d'ultrafiltration installées dans l'industrie laitière mondiale ; données utilisant les relevés de DE BoER et HIDDINK (1980) et les informations fournies par les Sociétés Abcor, Alfa-Laval, Dorr Oliver, Ladish Triclover, Pasilac, RhônePoulenc et S.F.E.C.

Evolution of membrane areas in the world dairy industry according datas of DE BOER and HIDDINK (1980) and of Abcor, Alfa-Laval, Dorr Oliver, Ladish Triclover, Pasilac, Rhône-Poulenc and S.F.E.C.

en dix ans et une prise en compte continue par les manufacturiers des connaissances acquises sur le comportement rhéologique des rétentats d'ultrafiltration ont donné à une technique de laboratoire ses lettres de créance en matière de fiabilité et de sécurité pour un emploi industriel. 


\section{PROGRES RECENTS EN MATIERE DE MEMBRANES ET D'EQUIPEMENTS}

La membrane constitue l'élément essentiel de la technique d'ultrafiltration. Ses qualités de stabilité chimique, physique et physico-chimique, mécanique voire microbiologique, conditionnent l'efficacité et les rendements technologique et économique des procédés. Le constituant essentiel des premières membranes commercialisées était l'acétate de cellulose. Ce type de membrane est maintenant pratiquement abandonné, sauf et c'est surprenant, en Amérique du Nord, en raison de ses limitations de tenue en température $\left(50^{\circ} \mathrm{C}\right.$ maximum), en $\mathrm{pH}$ (3 à 8 ) et aux agents oxydants, limitations correspondant peu avec les exigences de l'industrie laitière en matière de nettoyage et de désinfection. La seconde génération qui représente l'essentiel du «parc membranes» mondial actuel est constituée à partir de polymères de synthèse (surtout des dérivés polysulfoniques). Ce type de membranes, outre des performances accrues, présente par rapport aux membranes en acétate de cellulose, une meilleure tenue en température $\left(75^{\circ}\right.$ à $\left.80^{\circ} \mathrm{C}\right)$ et au $\mathrm{pH}$ (2 à 12). On lui reproche cependant une mauvaise résistance aux désinfectants chlorés, au compactage mécanique ainsi qu'une certaine réactivité électrochimique.

La troisième génération de membrane a été introduite sur le marché à la fin des années 1970. Plusieurs équipements industriels (de 100 à $200 \mathrm{~m}^{2}$ ) sont en fonctionnement, essentiellement en France. Sa nature minérale (zircone supportée par du carbone graphite) lui confère une grande stabilité thermique $\left(400^{\circ} \mathrm{C}\right.$ ), mécanique (40 bars) et physicochimique (toute l'échelle de $\mathrm{pH}$ ) très élevée qui trouve tout son intérêt lors du traitement de produits à très haute viscosité (Goudedranche et al., 1980 ; Mahaut et al. 1982). Grâce à la mise en œuvre récente de poudres de zircone à surface spécifique pratiquement doublée, le pouvoir de coupure de ces membranes minérales un peu trop élevé - 80000 pour les premières commercialisées - a été abaissé à un niveau permettant la rétention quasi totale des protéines laitières (Mahaut et al., 1982).

Les membranes d'ultrafiltration sont assemblées en modules selon quatre configurations spatiales:

- la configuration plane (épaisseur de la lame liquide variant entre 0,5 et $2,5 \mathrm{~mm}$ ) telle que celles proposées par les firmes RhônePoulenc, Dorr-Oliver et Pasilac ;

- la configuration tubulaire (diamètre variant entre 6 et $25 \mathrm{~mm}$ ) telle que celles proposées par les firmes Abcor, P.C.I., Wafilin et S.F.E.C.

- la configuration fibre creuse (diamètre de l'ordre du $\mathrm{mm}$ ) telle que celles proposées par les firmes Romicon et Nuclépore; 
- la configuration spirale (module plan enroulé autour d'un tube collecteur de perméat) telle que celles proposées récemment par les firmes Abcor et Ladish.

Chaque configuration présente ses propres avantages et inconvénients en matière de performances (exprimées en litres de produit traité ou de perméat recueilli par heure et par $\mathrm{m}^{2}$ de membrane), de coûts d'investissement (10 000 à $30000 \mathrm{~F} / \mathrm{m}^{2}$ de membrane environnée en 1982), d'énergie installée $\left(0,214 \mathrm{KW} / \mathrm{m}^{2}\right.$ pour la conception fibre creuse; $0,700 \mathrm{KW} / \mathrm{m}^{2}$ pour les conceptions plane et spirale; $1,000 \mathrm{KW} / \mathrm{m}^{2}$ pour la conception tubulaire), de durée de vie des membranes (les garanties des constructeurs s'étalent entre 1 et 3 ans), de facilité et de coût de nettoyage (les conceptions tubulaire et plane sont considérées comme les plus faciles à nettoyer par Glover et al., 1978) et d'encombrement spatial (selon Richard, 1974, les surfaces de membrane développées par $\mathrm{m}^{3}$ d'espace seraient dans les rapports 1 pour la conception tubulaire, 3 pour la conception plane et jusqu'à 50 pour la conception fibre creuse).

Dans une certaine mesure, les équipements récents prennent en compte l'évolution du comportement rhéologique des rétentats d'ultrafiltration en fonction de l'élévation de leur teneur en protéines. Les solutions retenues pour les étages dits de finition, outre la substitution de pompes volumétriques aux pompes centrifuges vont du raccourcissement du chemin membranaire : cartouches "courtes» et "ultra-courtes» de Romicon à une conception entièrement nouvelle du support de membrane : module 37 de Pasilac (fig. 2).

\section{PARAMETRES D'ULTRAFILTRATION}

La figure 3 schématise l'opération d'ultrafiltration dans le cas du traitement du lactosérum. La membrane agit comme un tamis visà-vis des éléments macromoléculaires du lactosérum; il s'ensuit une élévation du rapport protéines/substance sèche dans le rétentat. Le perméat, quant à lui, contient tous les éléments dissous du lactosérum : lactose, sels minéraux, azote non protéique, vitamines, etc. Sa substance sèche représente $88 \%$ de celle du lactosérum avant traitement.

L'optimisation du traitement du lait et de ses dérivés par ultrafiltration sur membrane passe naturellement par celle des débits de perméation, ce qui implique que soient connus les mécanismes d'établissement et d'évolution de la couche de polarisation ou "membrane dynamique " qui joue un rôle essentiel en la matière. La revue des différentes observations effectuées lors du traitement du lait et de ses dérivés nous a amené récemment (Maubois, 1982) à formuler l'hypothèse suivante quant au mécanisme de formation de la couche de polarisation. 


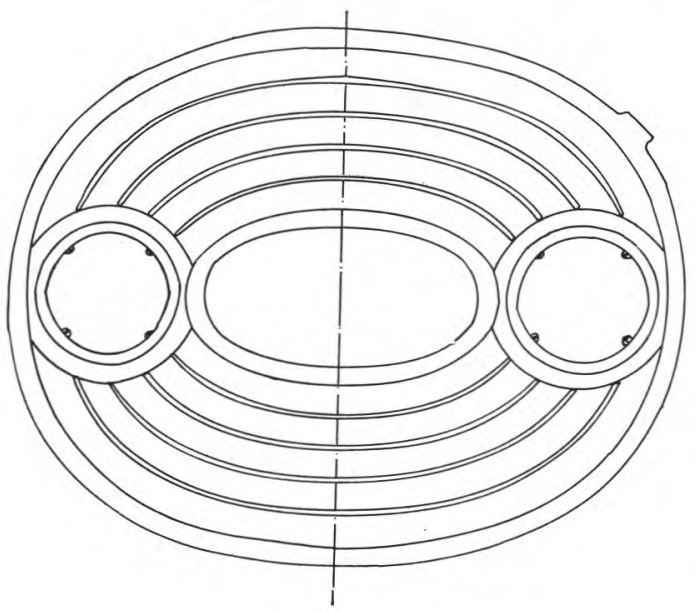

ULTRAFILTRATION DU LACTOSERUM fig. 2

Schéma du nouveau support 37 développé par Pasilac.

Schema of new 37 support developped by Pasilac.
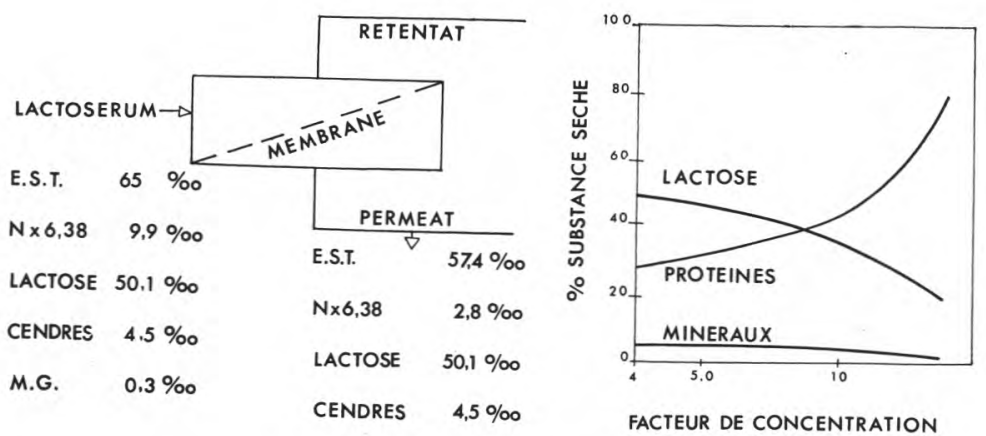

fig. 3

Composition schématique des produits obtenus lors de l'ultrafiltration de lactosérum.

Schematic composition of products obtained during ultrafiltration of
whey.

Dans un premier temps, la rétention par la membrane d'ultrafiltration des protéines du lait ou du lactosérum modifie brutalement les équilibres et les interactions existant entre ces composants 
macromoléculaires et ceux existant dans la phase aqueuse environnante, solution de lactose, de sels minéraux plus ou moins dissociés selon leur nature, d'azote non protéique, qui, elle, passe la barrière des pores de la membrane. Au niveau de cette barrière, à température supérieure à $20^{\circ} \mathrm{C}$ et au $\mathrm{pH}>6,0$, un état instable se crée notamment en ce qui concerne la solubilité des sels minéraux phosphocalciques. Il en découle ce qui pourrait être appelé un "colmatage primaire» par précipitation minérale intramembranaire. Cette hypothèse s'appuie sur les observations de Roger et al. (1976) qui ont montré que l'ultrafiltrat de lait ou de lactosérum doux était très instable aux températures supérieures à $20^{\circ} \mathrm{C}$. Dans le lait ou le lactosérum, cette précipitation minérale thermique ne se produit pas en raison de l'effet protecteur des protéines lorsqu'elles se trouvent en concentration supérieure à $0,7 \%$ (Brulé et al., 1978). Elle ne se produit pas non plus à un $\mathrm{pH}$ inférieur à 6,0 en raison de l'élévation de solubilité des sels phosphocalciques (Brulé, 1976).

Dans un second temps ou parallèlement, comme montré par Lee et Merson (1976), il y aurait ancrage sur la membrane des éléments figurés du lait ou du lactosérum : microorganismes, fines de caséine ou de paracaséine, débris cellulaires ou de membranes de globules gras (lipoprotéines) et formation d'un réseau maillé au sein duquel viendraient s'insérer les protéines du sérum: $\beta$-lactoglobuline et sérum albumine notamment. Ces protéines rempliraient progressivement tous les interstices du réseau pour former finalement un film composite de moins en moins perméable avec l'accroissement de la concentration en protéines du rétentat.

A partir de ces hypothèses sur la formation et la constitution de la couche de polarisation, différents modes d'action pour rapprocher les débits de perméation de leurs niveaux maxima sont envisageables :

- Au niveau de la technique elle-même: par le choix d'une température de fonctionnement représentant le meilleur compromis (en général 50 à $55^{\circ} \mathrm{C}$ ) entre une diffusion maximale du perméat au travers de la membrane, la maîtrise du développement bactérien et la non dénaturation thermique des protéines du lactosérum; par le choix aussi de paramètres hydrauliques du circuit rétentat propres à limiter au maximum "l'épaissement" de la membrane dynamique : vitesse de balayage élevée ( 2 à $5 \mathrm{~m} / \mathrm{s}$ ) en régime turbulent $(\operatorname{Re}>2000)$.

- Au niveau du produit soumis à ultrafiltration en réalisant un prétraitement (compatible avec les qualités recherchées pour le produit final) apte à éliminer tout ou partie des composants colmatant la membrane ou permettant de maintenir ouverte la structure de la couche de polarisation. Par exemple, parmi les nombreux prétraitements proposés pour le lactosérum soumis à ultrafiltration, il peut être cité : 
- l'élimination des constituants d'ancrage sur la membrane par microfiltration (Lee et Merson, 1976), par centrifugation (Olsen et Nielsen, 1976) ou par clarification (de Wit et de Boer, 1975) ;

- la prévention de la précipitation phosphocalcique intramembranaire lors du traitement de lactosérum doux par addition d'un sequestrant: citrate de sodium à $0,2 \%$ (Roger et al., 1976) ou hexamétaphosphate à $0,15 \%$ (de Boer et Hiddink, 1980), par déminéralisation préalable par électrodialyse ou par résines échangeuses d'ions ;

- le prétraitement thermique combiné avec un pré ou un postajustement du $\mathrm{pH}$ et éventuellement une addition d'ions calcium conduisant à la formation d'une couche de polarisation à structure relativement ouverte par la mise en jeu d'interactions protéinesminéraux encore incomplètement élucidées.

L'utilisation seule ou combinée de ces prétraitements du lactosérum a permis, en quelques années, de multiplier par 3 à 4 les débits de perméation des installations industrielles d'ultrafiltration du lactosérum (Muller et Harper, 1979).

\section{PROPRIETES ET UTILISATIONS DES CONCENTRES DE PROTEINES DE LACTOSERUM}

Les concentrés de protéines de lactosérum (CPL) obtenus par ultrafiltration sur membrane ont une très haute valeur nutritionnelle et d'excellentes propriétés fonctionnelles. Selon leur taux de purifi-

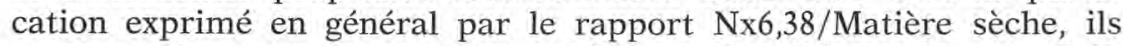
correspondent aux sources de protéines recherchées, soit pour l'alimentation des jeunes animaux, soit pour l'alimentation humaine. L'emploi de techniques complémentaires de séparation ou de fragmentation amène à préparer à partir de ces CPL des produits dérivés correspondant aux besoins et aux exigences de la nutrition thérapeutique.

\section{Qualité nutritionnelle}

La valeur nutritionnelle d'une protéine se juge en priorité par la comparaison de sa composition en acides aminés dits indispensables ou semi-indispensables à celle d'une protéine choisie comme référence. La figure 4 due à Roger (1979) montre que la composition des CPL est particulièrement équilibrée quelle que soit la protéine de référence choisie (œuf ou Fao-Who). Les CPL se distinguent en particulier par une teneur élevée en lysine, thréonine, tryptophane et cystéine, ce qui leur confère selon Forsum (1977) une valeur biologique exceptionnelle. 

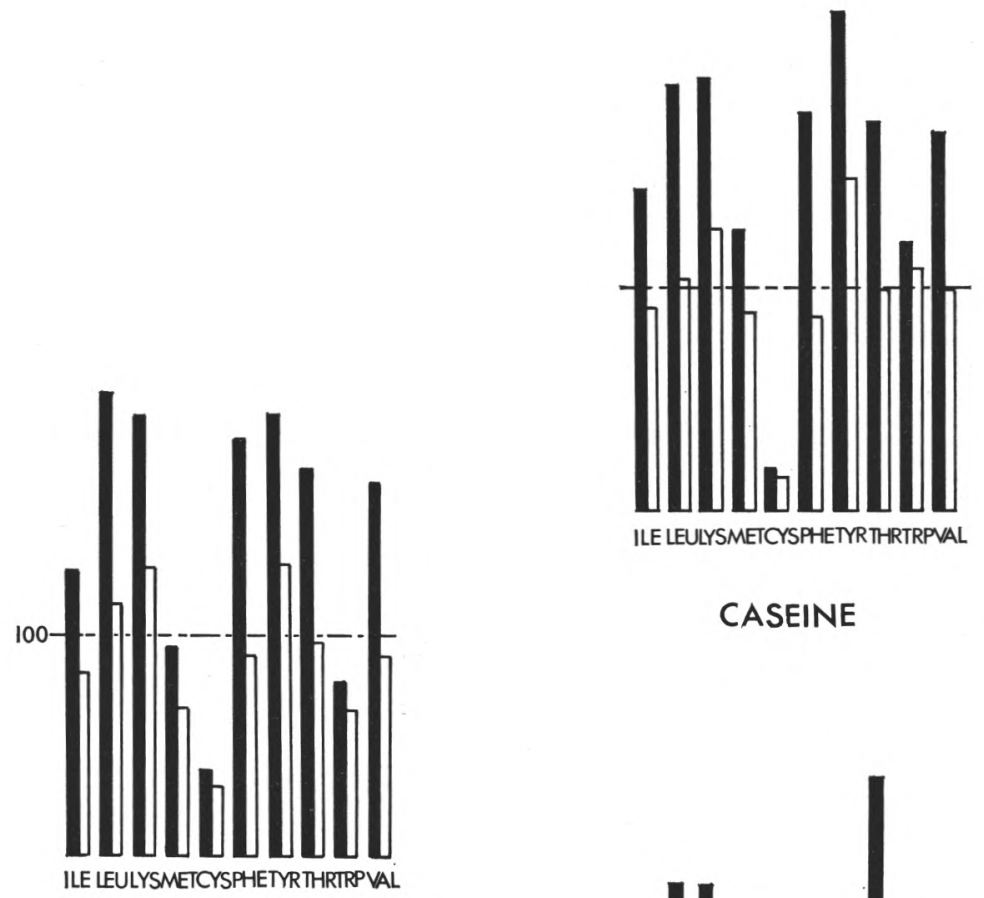

\section{CASEINE}

LAIT

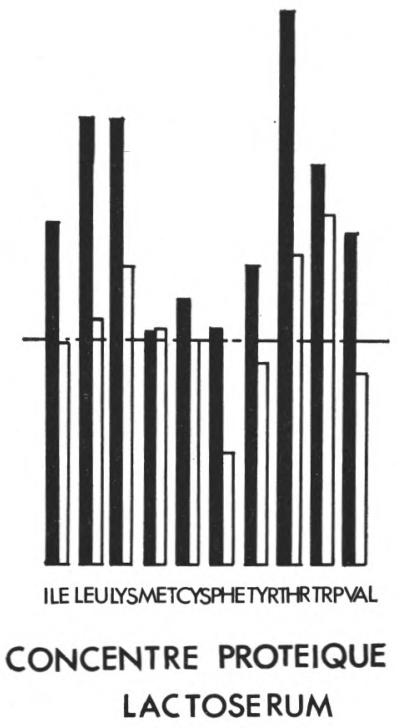

fig. 4

Valeur nutritionnelle comparée des C,P.L. par rapport à la protéine d'œuf (口) ou à la protéine F.A.O.-W.H.O. (匹).

Nutritional value of W.P.C. in comparison with egg protein (口) and F.A.O.-W.H.O. protein (-1). 


\section{Utilisation dans l'alimentation des jeunes animaux}

L'élimination d'environ $75 \%$ en volume d'un lactosérum sous forme de perméat par ultrafiltration sur membrane conduit à un rétentat ayant sensiblement le même rapport Nx6,38/substance sèche que le lait. Ce "lait homologue» peut parfaitement constituer la totalité de la fraction azotée de la formulation d'un aliment d'allaitement. L'utilisation digestive et métabolique d'un tel aliment par le veau préruminant se révèle au moins égale à celle d'un aliment classique à base de lait écrémé (Toullec et al., 1975 ; Stewart et al., 1974) et supérieure à celle d'aliments préparés à partir de protéines de sérum précipitées par la chaleur en milieu lactique (Sérac) ou en milieu chlorhydrique (lactoprotéines). Par ailleurs, l'utilisation pratique est facilitée en raison de la très bonne solubilité des protéines de sérum obtenues par ultrafiltration. La préconcentration par évaporation ou par osmose inverse du lactosérum multiplie par un facteur de 4 à 5 les performances des équipements d'ultrafiltration, ce qui réduit d'autant les coûts d'investissement, lors de la préparation de tels "laits homologues " (Goudedranche et al., 1976; de Boer et at., 1977).

\section{Utilisation en alimentation humaine}

La figure 5, due à de Wit et de Boer (1975), résume à la fois les principales propriétés fonctionnelles des CPL, les traitements technologiques qui permettent de les influencer et des exemples de produits dans lesquels ces propriétés des CPL sont utilisées. Les principaux avantages fonctionnels des CPL obtenus par ultrafiltration se situent au niveau (de Wit et de Boer, 1975; Morr, 1979) :

- de la solubilité sur toute l'échelle de $\mathrm{pH}$ (pour les protéines non dénaturées) ;

- de leur capacité de rétention de l'eau;

- de leur pouvoir gélifiant ;

- du pouvoir moussant.

De la capacité d'un additif protéique à lier et à structurer l'eau découlent des propriétés particulièrement fondamentales pour les industries agro-alimentaires tant sur le plan technologique (bon déroulement des processus enzymatiques et microbiens) que sur le plan économique (conservation de l'eau tout au long de la chaîne de production et de commercialisation). Les protéines du lactosérum fixant 2 fois plus d'eau liée non solvante que les caséines ou les protéines végétales (Berlin et al., 1973) soit environ 1,1 g par g de protéine et en structurant au total $5 \mathrm{~g}$ par $\mathrm{g}$ (de Wit et de Boer, 1975) constituent des ajouts fonctionnels de choix de plus en plus utilisés dans les industries de la charcuterie, de la salaisonnerie, des plats cuisinés (potages). 


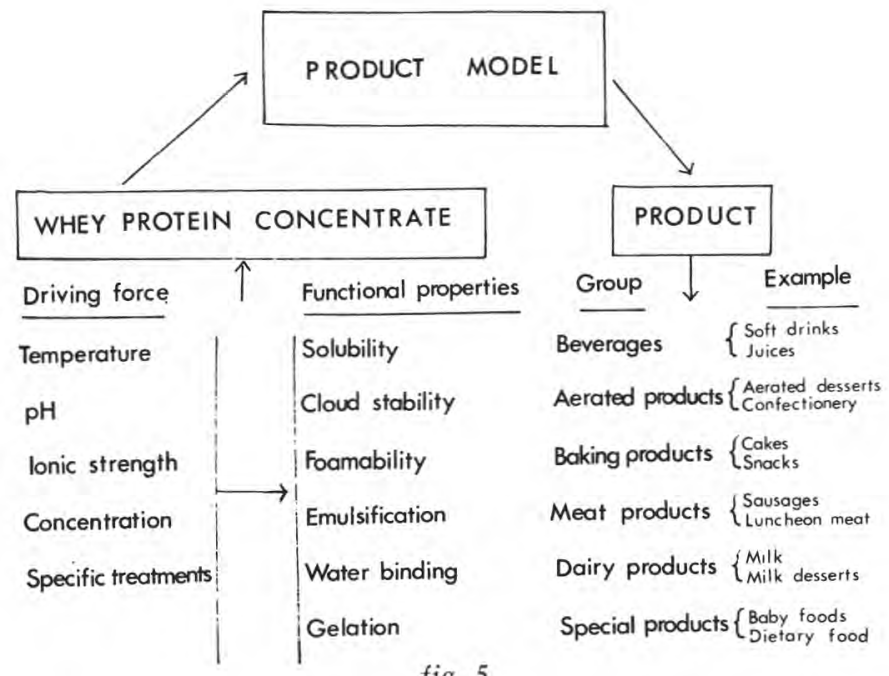

fig. 5

Schéma des principales propriétés fonctionnelles des C.P.L., des possibilités de les modifier et des produits dans lesquels elles interviennent (DE WIT et DE BOER, 1975).

Schema of main functional properties of W.P.C., the possibilities of altering them and the products in which they play a role (DE WIT and DE BOER, 1975).

La réactivité de leurs groupements sulfhydriles libres donne aux CPL d'intéressantes propriétés gélifiantes. En solution simple, un gel ferme et homogène, non redispersable, est obtenu après traitement à $95^{\circ} \mathrm{C}-30$ minutes, lorsque la teneur en protéines est supérieure à $4 \%$ (Pierre et al., 1978). En mélange avec du lait écrémé, un gel de type flan est obtenu par un traitement de $85^{\circ} \mathrm{C}-5$ minutes lorsque la teneur atteint $1,5 \%$, soit une teneur inférieure de moitié à celle requise pour obtenir un gel de mêmes caractéristiques à partir de blanc d'œuf (Mc Donough et al., 1974). Les gels obtenus avec les rétentats de lait soumis à un traitement thermique de $95^{\circ} \mathrm{C}$ 30 minutes sont dus à la matérialisation intra et extramicellaire des gels de protéines du lactosérum car le phosphocaséinate seul ne gélifie pas (Pierre et al., 1978).

Du fait de leur disponibilité, de leur coût modéré (en regard de celui du blanc d'œuf) et de leur capacité à former des mousses stables avec un gaz (en général l'air) les CPL peuvent prétendre à une large utilisation en pâtisserie industrielle. De très nombreux travaux ont été consacrés au pouvoir moussant des CPL et si les conclusions dégagées apparaissent, en première analyse, contradictoires quant à leur potentialité de se substituer totalement au blanc 
d'œuf, cela tient au fait que nombre d'auteurs n'ont pas pris en compte, dans leurs études, la présence de matière grasse dans les concentrés testés. En effet, les lipides résiduels, provenant pour l'essentiel de la membrane des globules gras, sont antagonistes de l'aptitude au moussage (Richert et al., 1974). Leur élimination par clarification (de Boer et al., 1977) donne aux CPL résultant les mêmes qualités moussantes que le blanc d'œuf. C'est probablement dans la modification de ces lipides résiduels que doit être recherché l'essentiel de l'augmentation de pouvoir moussant consécutive à divers traitements: hydrolyse thermoacide (Paquet et al., 1978) ajustement du $\mathrm{pH}$ (McDonough et al., 1974), addition de surfactant ionique (Richert et al., 1974), protéolyse pepsique limitée (Kuehler et Stine, 1974). Il n'en reste pas moins qu'une légère dénaturation thermique ou une protéolyse limitée doivent favoriser l'aptitude au moussage en rendant les protéines plus accessibles aux dénaturations interfaciales.

La teneur résiduelle en lipoprotéines des CPL est probablement aussi à l'origine de la variabilité des résultats constatés en matière de capacité émulsifiante. Il est vraisemblable que les protéines de sérum seules ont un pouvoir limité d'abaissement de la tension interfaciale entre une solution aqueuse et un lipide hydrophobe en raison de leur conformation globulaire et de la distribution relativement homogène dans leur séquence de groupements hydrophiles et hydrophobes (Morr, 1976).

Les CPL trouvent en raison de leur valeur nutritionnelle une large utilisation dans les aliments infantiles et dans la maternisation du lait de vache (rapport Caséine/Protéines totales amené de $80 \%$ à $40 \%$ ) mais selon Forsum (1974) une telle humanisation serait impropre car la protéine dominante du lactosérum de vache, la $\beta$-lactoglobuline, n'existe pas dans le lactosérum humain. Un véritable substitut du lait humain serait donc un lait de vache additionné d' $\alpha$-lactalbumine seule.

La préparation d'un produit enrichi en $\alpha$-lactalbumine lors du traitement du lactosérum par ultrafiltration a été décrite par Roger et Maubois (1981). Elle consiste à soumettre un lactosérum dont le $\mathrm{pH}$ a été au préalable ajusté à 6,6 et éventuellement clarifié par microfiltration ou décantation à une ultrafiltration en cascade sur deux équipements ayant le premier une porosité supérieure à 20000 et le second une porosité de l'ordre de 2000 (fig. 6).

\section{ULTRAFILTRATION DU LAIT}

La figure 1 montre que l'utilisation de l'ultrafiltration sur membrane pour le traitement du lait a pris plus de temps que pour le traitement du lactosérum. De nombreuses raisons sont à l'origine de 


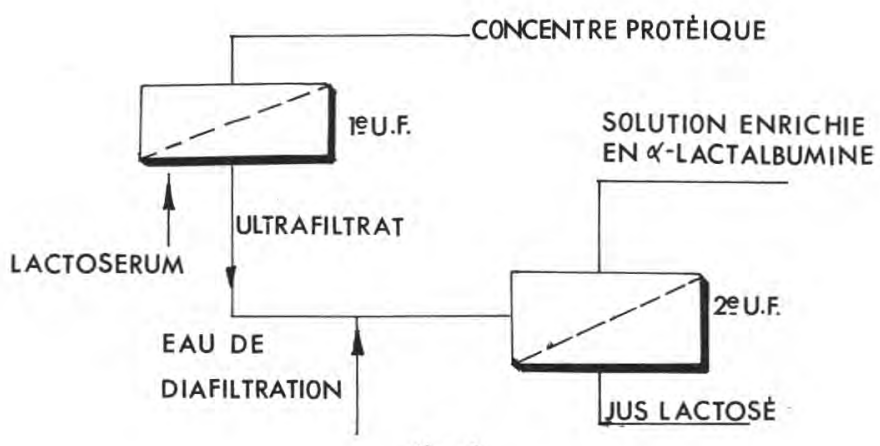

fig. 6

Schéma du procédé de préparation d'un produit enrichi en $\alpha$-lactalbumine par ultrafiltration en cascade (Roger et MaUbors, 1981).

Schema of the process for obtaining a product enriched in $\alpha$-lactalbumin by two steps ultrafiltration (ROGER and MAUBOIS, 1981).

ce décalage, la principale étant que pour la transformation du lait en fromage, cette technique ne peut, sauf à une récente exception, se substituer purement et simplement à l'opération d'égouttage mais exige la mise en place d'une technologie complète aboutissant aux produits souhaités par le consommateur.

L'opération qui est réalisée en soumettant du lait à l'ultrafiltration sur membrane correspond donc à celle que réalise le fromager lorsqu'il concentre par synérèse la matière grasse et les protéines du coagulum obtenu par action de la présure sur le lait. Le produit retenu par la membrane a sensiblement, en fin d'opération, la même composition et la même teneur en eau que le fromage que l'on souhaite préparer, aussi l'avons-nous appelé Préfromage liquide (Maubois et al., 1969). L'addition des «aides de fabrication » (levains - éventuellement sel — présure) conduit directement à un produit ayant la forme et les dimensions définitives du fromage désiré (fig. 7).

\section{En fromagerie}

Une revue exhaustive des différentes applications de ce procédé ayant atteint la taille industrielle: 120000 tonnes en 1981 selon les informations en notre possession ou décrites dans la littérature, ne relevant pas de notre propos au cours de ce colloque, nous nous contenterons de décrire brièvement l'application du procédé MMV à la fabrication de fromage Feta, de fromages à pâte demi--dure et de fromages à pâte fraîche.

La fabrication de fromage Feta dont le protocole est décrit dans la figure 8 constitue un exemple particulièrement démonstratif 


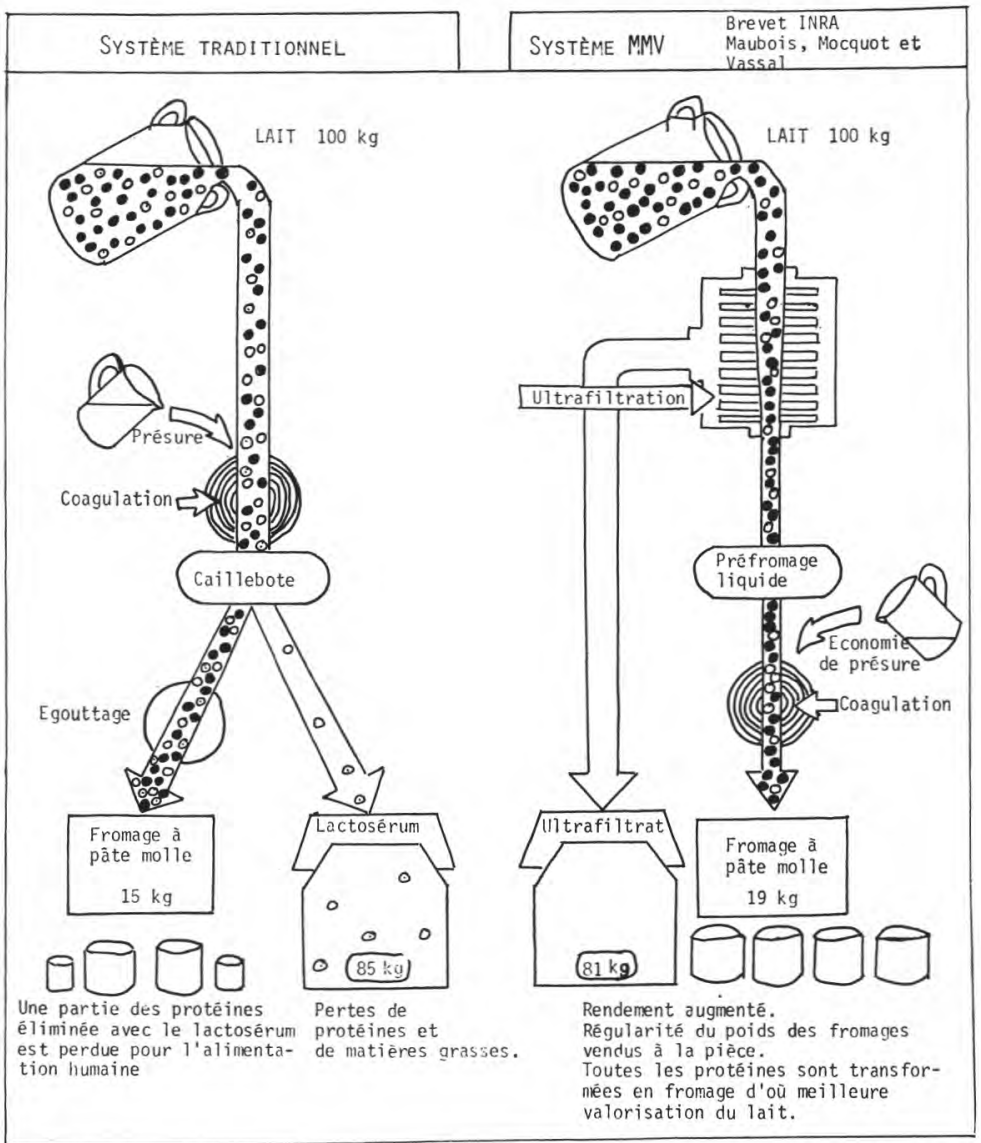

fig. 7

Schéma du procédé M.M.V.

Schema of M.M.V. process.

de la simplification d'une technologie fromagère grâce à l'emploi de l'ultrafiltration. La réduction des coûts découlant des innovations techniques réalisées au niveau du moulage dans le récipient de commercialisation et l'augmentation du rendement de transformation : $+32 \%$ (Hansen, 1977) jointe à une agressivité commerciale constante ont fait que cette production fromagère est passée chez nos amis danois, en moins de cinq ans, de quelques centaines de tonnes à 92000 tonnes (Bjerre, 1982) représentant ainsi $32 \%$ de la production fromagère globale de ce pays. 
FABRICATION DE FROMAGE FETA $40 \%$

(HANSEN, 1977)

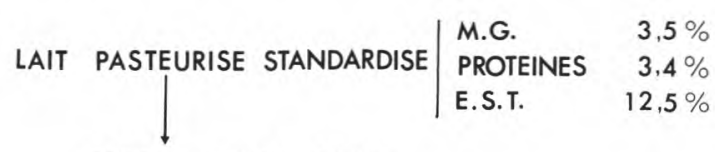

PRECHAUFFAGE $50^{\circ} \mathrm{C}$
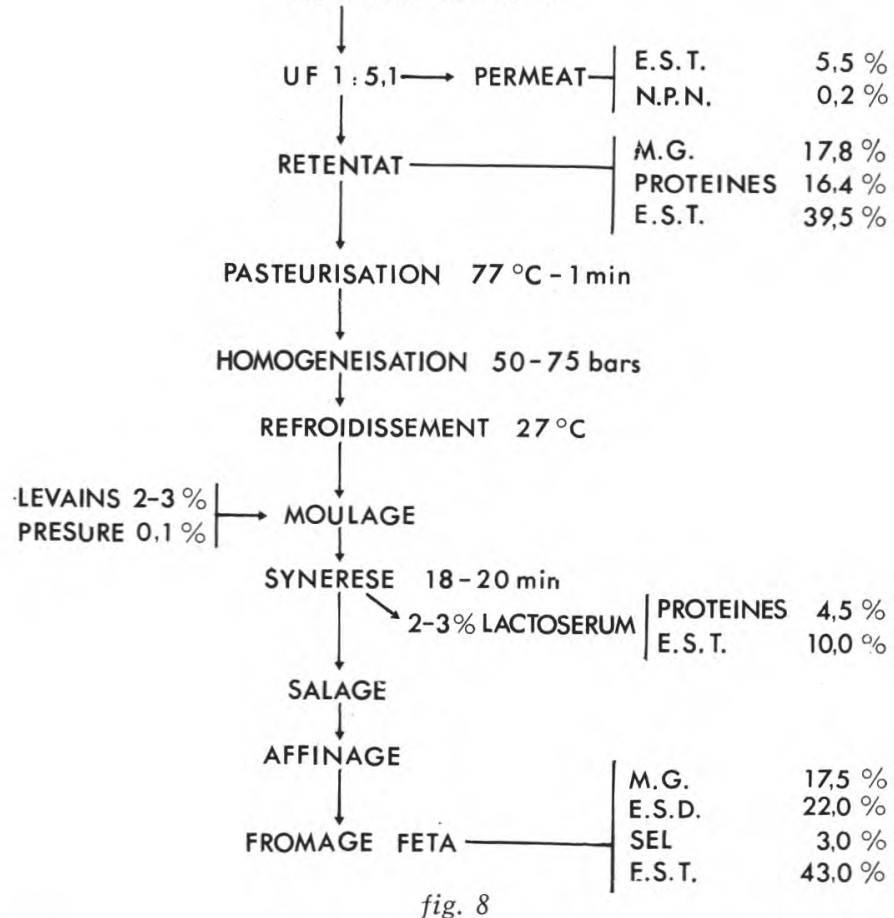

Protocole de fabrication du fromage Feta par le procédé M.M.V. (HANSEN, 1977).

Making of Feta cheese through M.M.V. process (Hansen, 1977).

Les progrès récents en matière d'équipements d'ultrafiltration (membranes minérales et conception d'équipements finisseurs) ont permis l'obtention répétitive avec une excellente fiabilité industrielle de préfromages à teneur en protéines supérieure à 21 g p. 100. De tels préfromages constituent des bases fromagères à partir desquelles une extraordinaire palette de produits entièrement nouveaux ou proches des fromages usuels peut être préparée, soit par action sur la nature du levain lactique ajouté, ou des autres additifs: enzymes, épices, etc., ou bien encore par action sur les conditions de 
transformation ou d'affinage. C'est dans cet esprit qu'il nous a paru intéressant d'étudier les possibilités de préparation d'un nouveau fromage à pâte demi-dure (teneur en substance sèche 50 à $52 \%$ ) développant une ouverture propionique au cours d'affinage (Ducruet et al., 1981) (fig. 9). C'est dans le même esprit que Delespaul et

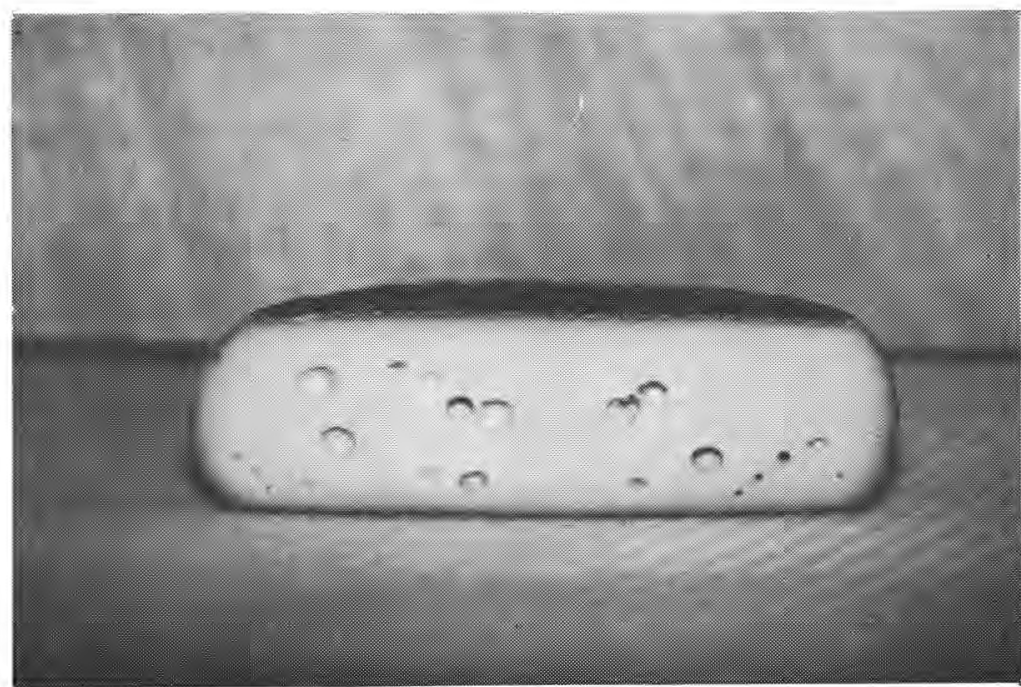

fig. 9

Fromage à pâte demi-dure et à ouverture propionique obtenu selon le procédé M.M.V. (Ducruet et al., 1981).

Semi-hard cheese with propionic eye opening obtained through M.M.V. process (DUCRUET et al., 1981).

Remars (1981) ont également décrit la fabrication de nouveaux fromages multicouches, "veinés " ou "marbrés " à partir de ces bases fromagères.

Les caractéristiques de résistance mécanique des membranes minérales d'ultrafiltration et leur «nettoyabilité » nous ont amené à réétudier l'ultrafiltration de lait acidifié et coagulé comme proposé par Stenne (1973) en substitution de l'équipement de centrifugation en fabrication de fromages à pâtes fraîches, l'ultrafiltration du lait liquide même préalablement maturé conduisant à des produits aux qualités organoleptiques incomplètement satisfaisantes. Les résultats obtenus (Mahaut et al., 1982) notamment en matière de qualité de produits et de performances d'ultrafiltration (fig. 10) sont suffisamment encourageants pour que soit envisagée une rapide insertion 


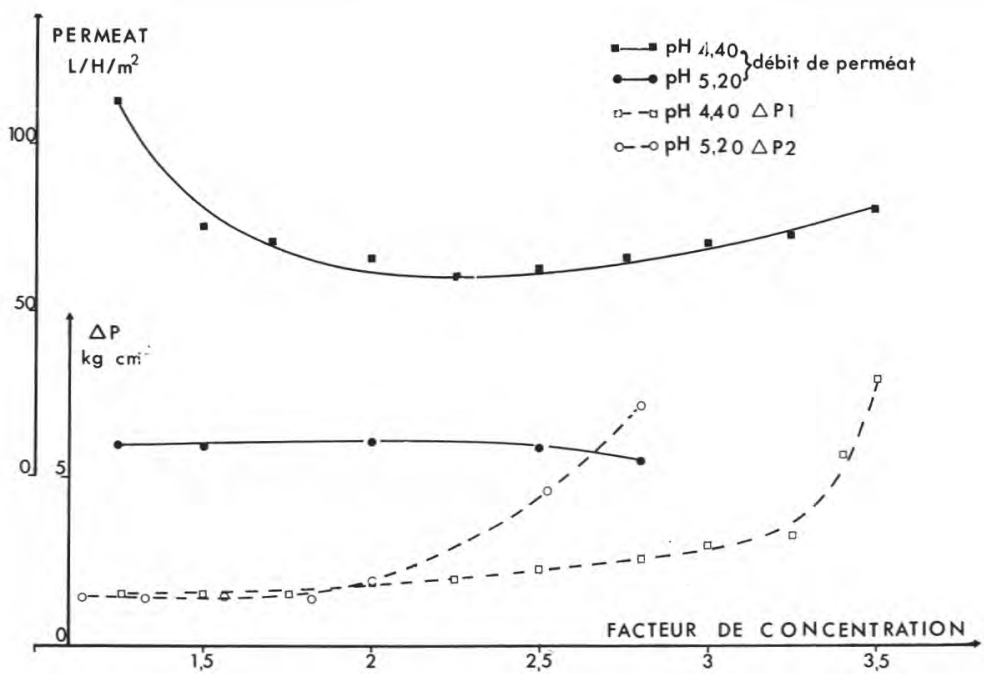

fig. 10

Flux de perméation observés lors de l'ultrafiltration de coagulum de lait à $\mathrm{pH}$ 4,6 (MAHAut et al., 1982).

Permeate flux observed during ultrafiltration of curd at pH 4.6 (MAHAUT et al., 1982).

de cette technologie dans l'industrie mondiale des fromages à pâtes fraîches.

\section{Ultrafiltration-thermisation du lait à la production}

En technologie agro-alimentaire, la démarche scientifique ne peut ni ne doit être partielle et limitée. Elle se doit d'être globalisée autant que faire se peut à l'ensemble du processus ou de la filière. Ainsi, en matière d'ultrafiltration sur membrane, nous sommes-nous posés la question de savoir si le niveau d'insertion retenu initialement (l'atelier de fromagerie) était le meilleur ou bien s'il devait être le seul.

Cinq séries de réflexions nous ont amené à envisager la possibilité d'insérer cette technique en couplage avec une thermisation au niveau du producteur de lait :

- l'évolution de la qualité bactériologique du lait collecté : en raison de la généralisation du refroidissement à la ferme et de l'espacement de la collecte du lait qui l'accompagne, la composition de la flore contaminante initiale du lait est modifiée à l'arrivée à l'usine. Les germes psychrotrophes, représentant à l'origine à peine $1 \%$ de la flore totale, deviennent dominants lorsque la durée de 
conservation à $4^{\circ} \mathrm{C}$ atteint 72 heures. Or, ces germes, s'ils sont détruits par les traitements thermiques habituels, présentent la fâcheuse propriété de produire des enzymes extracellulaires (protéases et lipases) très thermorésistantes (Alichandis et Andrews, 1977). La généralisation de la collecte 4 traites et la suppression du travail du week-end en atelier font que les laits subissent leur première thermisation 3,4 voire 5 jours après la traite, à un stade où la population critique en germes psychrotrophes $\left(10^{\circ}\right.$ germes $\left./ \mathrm{ml}\right)$ est atteinte ou dépassée (Auclair, 1979). De ce fait, la quasi-totalité des professionnels enregistre des défauts de fabrication ou de qualité, liés à la présence des enzymes produites par la flore psychrotrophe : gélification en cours de stockage des laits UHT (Adams et al., 1976), pertes de 2 à $3 \%$ du rendement en transformation fromagère (Aylward et al., 1980), défaut de rancidité dans les fromages et le beurre (Law et al., 1976). Une façon de remédier à ce problème de qualité nous a semblé être la réalisation d'un traitement thermique détruisant à un stade aussi proche que possible de la production la source initiale de contamination.

- Les économies d'énergie: la vache produisant un lait à $37^{\circ} \mathrm{C}$, pourquoi, dans le contexte actuel de renchérissement de l'énergie, le refroidir à $4^{\circ} \mathrm{C}$ pour l'amener ensuite à $72^{\circ} \mathrm{C}$ et le ramener enfin à basse température? Ne devrait-on pas le thermiser tout de suite en utilisant toutes les calories disponibles au niveau de la ferme et notamment celles de la vache et du condenseur de l'équipement de réfrigération?

- La valorisation respective des composants du lait : un examen systématique des valorisations des composants du lait montre qu'à l'exception de la transformation en lait de consommation ( $20 \%$ de la collecte), l'homme utilise peu, valorise mal 3 composants du lait: l'eau, le lactose, les sels minéraux solubles, ces deux derniers composants représentant à peu près $50 \%$ de la matière sèche du lait produit. Nous nous sommes donc posés la question: pourquoi refroidir, conserver, collecter, traiter avec des technologies coûteuses ces composants et ce, d'autant plus que les études récentes de Schingoethe (1976) et Thivend (1977) ont démontré qu'ils étaient très bien utilisés par l'animal producteur: la vache.

- Les progrès accomplis en matière d'équipement d'ultrafiltration: la fiabilité des membranes d'ultrafiltration de seconde et de troisième génération est telle que leur implantation au niveau de la production laitière peut s'envisager au sein d'un équipement automatisé et intégré de grande diffusion.

De ces réflexions a découlé une étude actuellement en cours, en collaboration avec E.D.F. et Alfa-Laval, sur la conception et la mise en œuvre d'une technologie avec l'équipement requis pour le traitement du lait dès la traite par ultrafiltration jusqu'à un facteur de concentration voisin de 2 , traitement suivi ou accompagné d'une thermisation du genre pasteurisation ( $\left.72^{\circ} \mathrm{C}-15^{\prime \prime}\right)$. 
Les premiers résultats obtenus (Bénard et al., 1981) portant sur une période d'expérimentation de 18 mois sur équipement prototype permettent d'affirmer la faisabilité de la combinaison ultrafiltration + thermisation sur le lieu de production. La qualité bactériologique de la nouvelle matière première laitière (rétentat 2 thermisé) est illustrée par la figure 11). Le nombre de germes mésophiles dans le cumul sur 4 jours de 8 traites reste très inférieur en moyenne à 10000 germes, ce qui autorise une collecte bi-hebdomadaire.

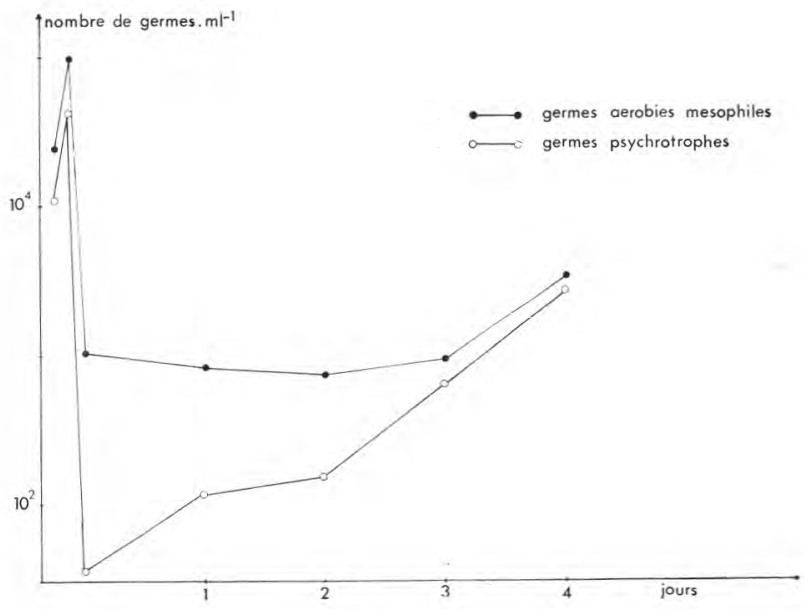

fig. 11

Evolution de la qualité bactériologique du rétentat 2 thermisé sur un cumul consécutif de huit traites.

Evolution of bacteriological quality of eight UF thermized retentates provided by successive milkings.

Parallèlement, les premières observations préliminaires réalisées sur les conséquences physico-chimiques et biochimiques du traitement envisagé et sur la conservation au froid du produit sont très encourageantes quant à son aptitude aux diverses transformations laitières. Ces observations seront confirmées et précisées au cours des prochains mois par la mise en place prochaine de 6 équipements permettant l'obtention et le traitement de quantités significatives, industriellement parlant, de rétentat 2 thermisé.

Si cette technologie se trouvait généralisée, c'est toute l'économie, voire la structure de la filière lait qui se trouverait remise en cause. En effet, outre l'amélioration générale de la qualité du lait collecté et des produits résultants, toutes les capacités qu'elles soient 
de collecte, de transport, de fabrication (écrémage, pompage, pasteurisation, fromagerie, évaporateurs, tours, etc.) se trouveraient doublées, la composition des produits serait modifiée (poudres de lait et de lactosérum notamment), le système de paiement du lait, les aides financières pour le soutien du marché du lait seraient à revoir.

\section{BIOTECHNOLOGIES A MEMBRANES}

La technologie du réacteur enzymatique à membrane (fig. 12) constitue la technique de fragmentation la plus souple et la plus adaptée aux composants des liquides biologiques. En effet, le confinement de l'enzyme dans une volume très restreint offre la possibilité de réaliser la ou les réactions avec un rapport enzymes (s)-

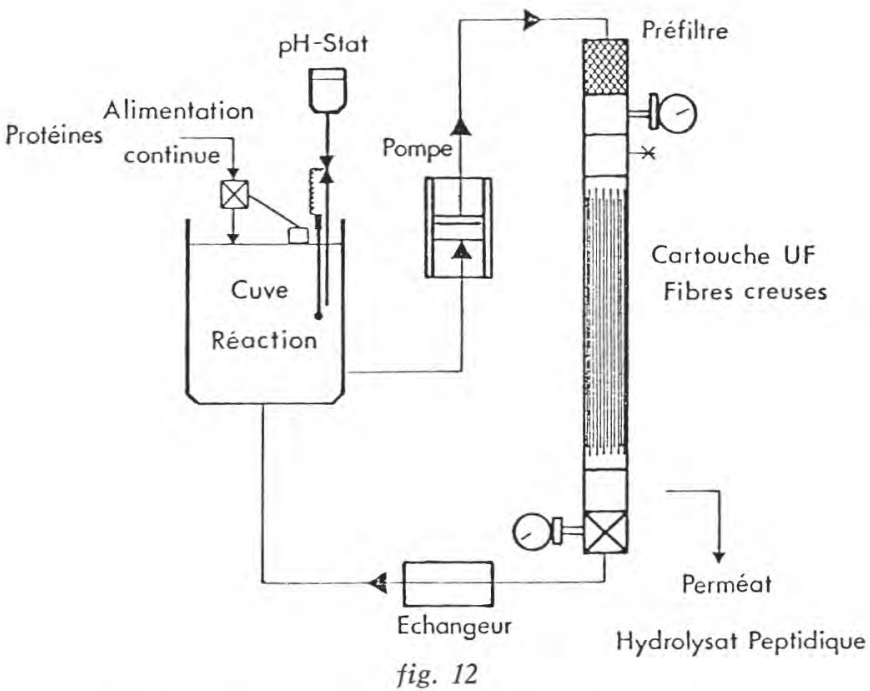

Schéma d'un réacteur enzymatique à membrane.

Membrane enzymatic reactor.

substrat (s) très élevé, proche des conditions physiologiques et ce dans des conditions économiques non prohibitives, l'enzyme étant récupérée; l'opération peut être menée en continu ou en séquentiel soit avec des enzymes pures, soit avec des systèmes multienzymatiques (mélanges de protéases et de lipases par exemple) à condition que les paramètres d'activité soient compatibles; enfin, la membrane d'ultrafiltration, outre l'élimination au fur et à mesure de leur 
production des produits d'hydrolyse, peut servir par ses propres caractéristiques de porosité de moyen de fractionnement complémentaire.

\section{Fragmentation des protéines de lactosérum}

La fragmentation en réacteur enzymatique à membrane des concentrés de protéines de lactosérum (CPL) permet d'aboutir à des produits originaux correspondant aux besoins de nutrition existant en thérapeutique hospitalière pour la suppléance des fonctions digestives déficientes ou bien pour stimuler le retour de ces dernières à une activité quasi normale (Roger, 1979). Le procédé que nous avons développé comporte les étapes suivantes:

- préparation d'un CPL à 70-90 $\mathrm{g}$ de protéines/1;

- clarification de ce CPL par microfiltration soit en prétraitement du lactosérum avant ultrafiltration, soit après;

- introduction du CPL dans le réacteur enzymatique avec les conditions opératoires suivantes: température voisine de $40^{\circ} \mathrm{C}$; rapport enzyme/substrat voisin de $12 \%$; enzyme utilisée : pancréatine; $\mathrm{pH}$ maintenu à 8,5 par addition de $\mathrm{KOH}$; pouvoir de coupure de la membrane : 5000 ;

- obtention en continu d'un hydrolysat peptidique dont les caractéristiques sont illustrées par le diagramme d'élution représenté dans la figure 13. Tous les peptides obtenus ont un poids inférieur à 2000 avec une dominance se situant entre le dipeptide et le décapeptide. La teneur en acides aminés libres est inférieur à $10 \%$.

Les hydrolysats obtenus selon ce procédé correspondent aux besoins nutritionnels azotés de malades souffrant de mucoviscidose ou de fibrose kystique du pancréas, d'insuffisance rénale ou bien d'atteinte infectieuse et inflammatoire de la paroi intestinale (Roger, 1979). Ils constituent l'essentiel de la formulation azotée de ce qui est appelé les aliments de réanimation. Selon Mendy (1980), les besoins potentiels en ce type de produits représentent plusieurs milliers de tonnes de protéines pures par an au niveau mondial, c'est dire qu'une telle application peut représenter un débouché appréciable pour les protéines de lactosérum obtenues par ultrafiltration.

\section{Fragmentation des caséines}

Les groupements phosphorylés des caséines jouent un rôle fondamental en technologie laitière et fromagère et en schématisant quelque peu, c'est en intervenant sur leur aptitude à sequestrer le calcium que le fromager crée les conditions dans lesquelles vont se mettre en place les mécanismes de l'affinage. Mais sur un autre plan, les résultats récemment acquis par Mykannen et Wassermann, 
$\mathrm{pH} 3$

(b)

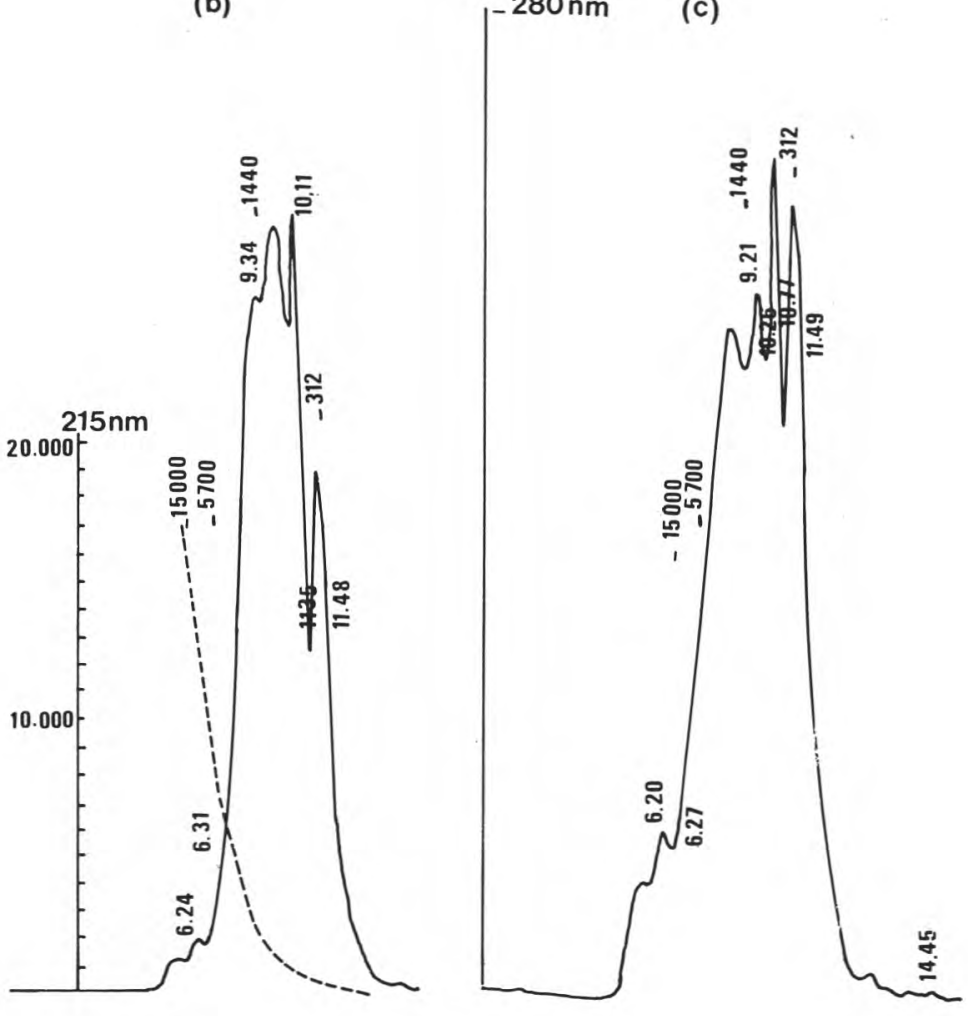

$280 \mathrm{~nm} \quad \mathrm{pH}$

(c)

fig. 13

Diagramme d'élution des hydrolysats peptidiques observés en perméation de gel (HPLC ; G 5000) à deux longueurs d'ondes (Roger et MaUboIs, 1981).

Eluting diagram of peptidic hydrolysates in gel permeation (HPLC; $G$ 5000) at two wavelengthes (ROGER and MaUBoIs, 1981).

(1980), et Mathan et al. (1979) suggèrent que les séquences originales des caséines du lait: enchaînement de 3 ou 4 phosphosérines consécutives auraient un rôle essentiel dans la physiologie de la digestion au niveau de l'absorption intestinale des éléments minéraux: calcium, fer, oligo-éléments. Il est possible aussi que ces séquences phosphopeptidiques interviennent également dans les mécanismes inducteurs de la sécrétion de chymosine.

La figure 14 indique un des schémas de préparation récemment proposés par Brulé et al. (1980) à partir d'une solution de caséinate de $\mathrm{Na}$ ou de $\mathrm{K}$. Il comporte les étapes suivantes: 


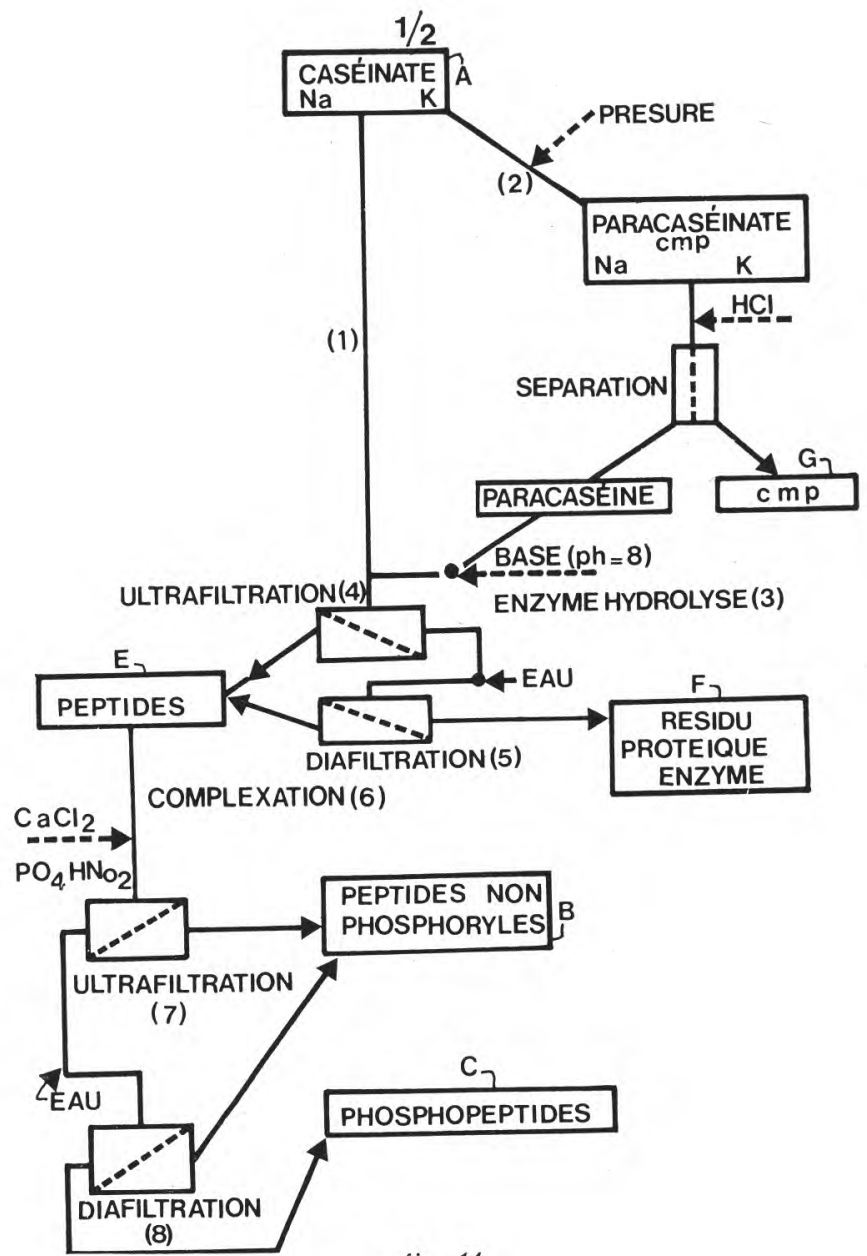

fig. 14

Schéma de préparation de phosphopeptides à partir de caséinate. Making of phosphopeptides from sodium or potassium caseinate.

- hydrolyse pancréatique d'une solution de caséinate ajustée à $\mathrm{pH}$ 8,0 en réacteur enzymatique à membrane;

- complexation des séquences phosphopeptidiques par addition de chlorure de calcium et de phosphate disodique, ce qui entraîne une polymérisation jusqu'à une taille moléculaire élevée;

- séparation et purification par ultrafiltration sur membrane de ces séquences phosphopeptidiques; 

à $\mathrm{pH} 4,6$;

- éventuellement solubilisation par acidification chlorhydrique

- concentration et séchage selon les technologies classiques.

Les phosphopeptides obtenus sont caractérisés par un rapport Ser/acides aminés totaux compris entre 8 et $20 \%$ selon les modalités opératoires et le produit de départ, un taux d'acides aminés aromatiques inférieur à $4 \%$ et une composition de cendres tout à fait particulière comme le montre l'exemple de composition suivant:

\begin{tabular}{|c|c|c|}
\hline - Teneur en $N \times 6,38 \ldots$. & 799 & $\mathrm{~g} / \mathrm{k}$ \\
\hline Cendres $\ldots \ldots \ldots \ldots$ & 203 & $\mathrm{~g} / \mathrm{kg}$ \\
\hline$P \quad \ldots \ldots \ldots \ldots \ldots$ & 38,7 & $\mathrm{~g} / \mathrm{kg}$ \\
\hline $\mathrm{Ca} .$. & 63,2 & $\mathrm{~g} / 1$ \\
\hline $\mathrm{Mg}$. & 0,60 & \\
\hline $\mathrm{Na} \ldots$ & 4,8 & \\
\hline & 19,9 & \\
\hline
\end{tabular}

Ainsi donc, le phosphore et le calcium représentent respectivement $19 \%$ et $31 \%$ de cendres. A pH 7,2, $90 \%$ du Ca et du P sont associés aux peptides. Ces peptides, malgré une teneur élevée en phosphate de calcium présentent une excellente solubilité, de l'ordre de $25 \%$, ce qui est dû aux teneurs élevées en acide glutamique $(30 \%)$. Ces phosphopeptides, associés ou non avec du calcium, ont un excellent pouvoir chelatant des oligo-éléments; ils peuvent selon les éléments en fixer de 5 à $12 \%$ de leur poids sec.

\section{Bibliographie}

AdAMs (D. M.), BARACH (J. T.), SPECK (M. L.) (1976). - Effect of psychotrophic bacteria on raw milk proteins and stability of milk proteins to ultrahigh temperature treatment. J. Dairy Sci., 59, 823.

Alichandis (E.), Andrews (A. T.) (1977). - Some properties of the extracellular protease produced by the psychrotrophic bacterium Pseudomonas fluorescens strain. Biochim. Biophys. Acta, 485, 424-433.

Auclair (J.) (1979). - Journée d'étude 1979 de l'I.E.S.I.E.L. Effets des techniques de réfrigération et de ramassage du lait sur la qualité bactériologique. Rev. Lait Fr. (378), 37-39.

Aylward (E. B.), O'Leary (J.), Langlois (B. E.) (1980). - Effect of milk storage on cottage cheese yield. J. Dairy Sci., 63, 1819-1825.

Benard (S.), Maubois (J. L.), TARecK (A.) (1981). - Ultrafiltration-thermisation du lait à la production: aspects bactériologiques. Lait, 61, 435-457.

Berlin (E.), Kliman (P. G.), Anderson (B. A.), Pallansch (M. J.) (1973). - Water binding in whey protein concentrates. J. Dairy Sci., 56, 984-987.

BJERRE (P.) (1982) + Communication personnelle.

BRULÉ (G.) (1976). - Résultats non publiés.

Brulé (G.), Real del Sol (E.), Fauquant (J.) (1978). - Mineral salts stability in aqueous phase of milk: influence of heat treatment. J. Dairy Sci., 61, 12251232.

Brulé (G.), Roger (L.), Fauquant (J.), Piot (M.) (1980). - Procédé de traitement d'une matière à base de caséine contenant des phosphocaséinates de cations monovalents et leurs dérivés. Produits obtenus et applications. Brevet français $\mathrm{n}^{\circ} 8002281$. 
De Boer (R.), De Wit (J. N.), Hiddink (J.) (1977). - Processing of whey by means of membranes and some applications of whey proteins concentrates. $J$. Soc. Dairy Technol., 30, 112-120.

DE BoER (R.), Hiddink (J.) (1980). - Membrane processes in the dairy industry : state of art. Desalination, 35, 169-192.

Delespaul (G.), Remars (J.) (1981). - Procédé de préparation de produits laitiers, en particulier de fromages multicouches et de fromages marbrés, à partir de rétentats ultrafiltrés, et nouveaux produits ainsi obtenus. Brevet français $\mathrm{n}^{\circ} 2475361$.

De Wit (J. N.), De BoER (R.) (1975). - Ultrafiltration of cheese whey and some functional properties of the resulting whey protein concentrate. Neth. Milk Dairy J., 29, 198-211.

De Wit (J. N.), De BoeR (R.) (1975). - Procédé de clarification de liquides contenant des protéines de petit lait. Brevet français $n^{\circ} 7635143$.

Ducruet (P.), Maubois (J. L.), Goudedranche (H.), Pannetier (R.) (1981). - Eléments de fabrication de fromages à pâte demi-dure et à ouverture propionique selon le procédé M.M.V. Techn. Lait. (957), 13-16.

Forsum (E.) (1974). - Nutritional evaluation of whey protein concentrates and their fractions. J. Dairy Sci., 57 (6), 665-670.

Forsum (E.) (1977). - Use of a whey protein concentrate as a supplement to maize, rice and potatoes. A chemical and biological evaluation using growing rats. J. Nutr. (105), 147-153.

Glover (F. A.), Skudder (P. J.), Stothart (P. H.), Evan (E. W.) (1978). - Reviews of the progress of dairy science: reverse osmosis and ultrafiltration in dairying. J. Dairy Res., 45, 291-318.

Goudedranche (H.), Maubois (J. L.), Van Opstal (C.), Piot (M.) (1976). - Préparation d'un lait de remplacement par ultrafiltration sur membrane de lactosérum préconcentré par évaporation. Rev. Lait. Fr. (345), 521-532.

Goudedranche (H.), Maubors (J. L.), Ducruet (P.), Mahaut (1980). - Utilization of the new mineral ultrafiltration membranes for making semi-hard cheeses. Desalination, 35, 243-258.

HANSEN (R.) (1977). - Feta cheese production by ultrafiltration. Nordeurop. Mejeri Tidssk., 9.

KueHler (C. A.), Stine (C. M.) (1974). - Effect of enzymatic hydrolysis on some functional properties of whey protein. J. Food Sci., 39, 379-382,

LaW (B.A.), Sharpe (H. E.), Chapman (H. R.), 1976. The effect of lipolytic Gram negative psychotrophs in stored milk on the development of rancidity in Cheddar cheese. J, Dairy Res., 43, 459.

Lee (D. N.), Merson (R. L.) (1976), - Prefiltration of cottage cheese whey to reduce fouling of ultrafiltration membranes. J. Food Sci., 41, 778-786.

McDonough (F. E.), Hargrove (R. E.), Mattingly (W. A.), Posati (L. P.), Alford (J.A.) (1974). - Composition and properties of whey protein concentrate from ultrafiltration. J. Dairy Sci., 57, 1438-1443.

Mahaut (M.), Maubois (J. L.), Zink (A.), Pannetier (R.), Veyre (R.) (1982) Eléments de fabrication de fromages frais par ultrafiltration sur membrane de coagulum de lait. Techn. Lait. (961), 9-13.

Mathan (V. I.), Baker (S. J.), Sood (S. K.), Ramachandran (K.), Ramalingaswami (V.) (1979). - The effects of ascorbic acid and protein supplementation on the response of pregnant women to iron, pteroylglutamic acid and cyanocobalamin therapy. Br. J. Nutr., 42, 391-398.

Maubois (J. L.), Mocouot (G.), Vassal (L.) (1969), - Procédé de traitement du lait et des sous-produits laitiers. Brevet français $\mathrm{n}^{\circ} 2052121$. 
Maubois (J. L.) (1982). - Les protéines du lactosérum extraites par ultrafiltration, dans: Protéines animales; extraits, concentrés et isolats en alimentation humaine, édité par Adria-Lavoisier (sous presse).

MENDY (F.) (1979). - Communication personnelle.

MorR (C. V.) (1976). - Whey protein concentrates : an update. J. Food Technol., $30,18-42$.

MoRR (C. V.) (1979). - Functionality of whey protein products. N.Z. J. Dairy Technol., 14 (2), 185-194.

MUller (L. L.), HaRPeR (W. J.) (1979), - Effects on membrane processing of pretreatments of whey. J. Agric. Food Chem., 27 (4), 662-664.

MyKKANEN (H. M.), WASSERMAN (R. H.) (1980). - Enhanced absorption of calcium by casein phosphopeptides in rachitic and normal chicks. J. Nutr., 110, 2141-2148.

Olsen (O. J.), Nielsen (J. O.) (1976). - Principles for dimensioning and construction of a DDS ultrafiltration plant for whey treatment. In : Danish Dairy Industry... Worldwide. Cheese. Hiallese, Denmark; Danish Dairy Managers Association, 64-65.

Paouet (D.), Thou (K. S.), Alais (C.) (1978). - Obtention de produits moussants alimentaires par hydrolyse ménagée des protéines de lactosérum de fromagerie. Ind. Alim. Agric., 95, 161-168.

Pierre (A.), Brulé (G.), Fauduant (J.) (1978). - Influence des traitements thermiques sur les propriétés physicochimiques des rétentats obtenus par ultrafiltration de lait de vache et de lait de chèvre. I. Dénaturation des protéines solubles. Lait, 58 (569-570), 646-662.

Pierre (A.), Brulé (G.), Fauduant ( $\mathrm{J}_{+}$) (1978). - Influence des traitements thermiques sur les propriétés physicochimiques des rétentats obtenus par ultrafiltration de lait de vache et de lait de chèvre. II. Modifications des propriétés rhéologiques du lait de vache. Lait, 58 (579-580), 575-594.

RICHARD (A.), 1974. - Communication personnelle.

Richert (S. H.), Morr (C. V.), CoONey (C. M.) (1974). - Effect of heat and other factors upon foaming properties of whey protein concentrates. J. Food Sci., $39,42-48$.

Roger (L.), Thapon (J.L.), Maubois (J. L.), Brulé (G.) (1976). - Hydrolyse du lactose contenu dans l'ultrafiltrat de lait ou de lactosérum en réacteur enzymatique à membrane. Lait, 56 (551-552), 56-75.

Roger (L.) (1979), - Contributions à la recherche d'une meilleure utilisation en alimentation humaine des composants glucidiques et proétiques du lactosérum grâce à l'emploi des techniques à membranes. Thèse d'Ingénieur Docteur, E.N.S.A., Rennes.

Roger (L.), Maubois (J.L.) (1981). - Actualités dans le domaine des technologies à membrane pour la préparation et la séparation des protéines laitières. Rev. Lait. Fr. (400), 67-75.

Schingoethe (D. J.) (1976), - Whey utilization in animal feeding: a summary and evaluation. J. Dairy Sci., 59 (3), 556-570.

STENNE (P.) (1973). - Procédé de fabrication d'aliments protéiques, notamment de fromages. Brevet français $n^{\circ} 2232999$.

Stewart (J.A.), Muller (L. L.), Griffin (A. T.) (1974). - Use of whey solids in calf feeding. Aust. I. Dairy Technol., 29, 53-58.

Thivend (P.) (1977). - Utilisation de l'ultrafiltrat de lactosérum dans l'alimentation du ruminant. Econ. Agri. (2).

Toullec (R.), Frantzen (J. F.), Maubois (J. L.), Pion (R.) (1975). - Utilisation digestive par le veau préruminant des protéines de lactosérum traitées par ultrafiltration sur membrane. Techn. Lait. (828), 17, 21, 51. 